\title{
Tecnologias digitais como metodologia de aprendizagem na educação especial
}

\author{
Digital technologies as a learning methodology in special \\ education
}

\author{
Kelly Maia Cordeiro ${ }^{1}$ \\ Mirna Juliana Santos Fonseca ${ }^{2}$
}

\section{Resumo}

$\mathrm{Na}$ fase escolar, uma das questões é o aprendizado de conceitos científicos que se materializam nos conteúdos das disciplinas. Tal problemática tem sua discussão ampliada quando se trata de alunos com deficiência intelectual. A fim de abordar a produção audiovisual com o uso de tecnologias digitais da informação e comunicação (TDIC) para aprendizagem de um grupo de adolescentes com deficiência intelectual, o artigo objetiva descrever e analisar o processo experienciado por esse grupo, ao produzir uma animação, com o uso do celular, sobre o conteúdo escolar "Relações entre seres vivos". O aporte teórico-metodológico baseia-se na perspectiva histórico-cultural e em conceitos contemporâneos sobre a TDIC na educação. Participaram da pesquisa cinco alunos com deficiência intelectual, matriculados no $5^{\circ}$ e $6^{\circ}$ anos de escolarização do ensino fundamental de uma escola pública do interior do Rio de Janeiro. Utilizamos para análise o material produzido durante a atividade e os respectivos registros em fichas de acompanhamento. Como principais resultados,

1 Doutoranda em Educação no Programa de Pós-Graduação em Educação da Pontificia Universidade Católica do Rio de Janeiro (PUC-Rio). Mestre em Educação pela Universidade Federal do Estado do Rio de janeiro (Unirio). Bolsista CAPES. Integrante do Grupo de Pesquisa Educação e Mídia (Grupem)- PUC-Rio e Observatório de Educação Especial e Inclusão Educacional (ObEE)- UFRRJ. Professora na rede municipal de Angra dos Reis-RJ.

2 Doutora em Educação pela PUC-Rio. Realizou estudos de Pós-doutorado no Programa de Pós-Graduação em Educação da Universidade Católica de Petrópolis (UCP-Rio). Mestra em Educação pela Unirio. Vice-Coordenadora Grupem/PUC-Rio. E-mail: mirnajuliana@gmail.com.

Interfaces da Educ., Paranaíba, v.11, n.31, p. 388 - 412, 2020 
apontamos como propositivo o desenvolvimento das habilidades de comunicação (no contexto das narrativas em diferentes formatos), habilidades sociocognitivas (trabalhar em equipe e tomar parte das decisões) e habilidades técnicas relacionadas à linguagem audiovisual.

Palavras-chave: Aprendizagem; Deficiência Intelectual; Produção audiovisual; Animação.

\section{Abstract}

In the academic phase, one of the questions is the learning of scientific concepts that materialize in the contents of the disciplines. Such problematic has its discussion expanded when it comes to the students with intellectual disability. In order to approach audiovisual production with the use of digital information and communication technologies (DICT) for the learning a group of adolescents with intellectual disabilities, the article aims to describe and analyze of the process experienced by this group, when producing an animation, with the use of the cellular, on the school content "Relationships between living beings". The theoretical-methodological contribution is based on the historical-cultural perspective and contemporary concepts on DICT in education. Five students with intellectual disabilities enrolled in the 5th and 6th years of elementary school attendance at a public school in the interior of Rio de Janeiro participated in the study. We used for analysis the material produced during the activity and the respective records in accompanying records. As main results, we propose the development of communication skills (in the context of narratives in different formats), sociocognitive skills (teamwork and decision making) and technical skills related to the audiovisual language.

Keywords: Learning; Intellectual disability; Audiovisual production; Animated film. 


\section{Introdução}

A aprendizagem dos alunos com deficiência intelectual vem sendo pesquisada por diferentes perspectivas (KASSAR, 2013; MENDES, 2006; PAIXÃO; OLIVEIRA, 2018; PLETSCH, 2014) de modo a romper com o constructo de que esse sujeito não aprende, mesmo estando na escola. Sabese que essa instituição tem como finalidade proporcionar o aprendizado dos conhecimentos acumulados pela humanidade, apropriando-se das produções científicas originadas do trabalho realizado pelo homem através da mediação dos instrumentos culturais (PINO, 1993).

No contexto escolar, um dos fatores que conduz o aprendizado dos conteúdos formais é a metodologia utilizada pelo professor. A forma a partir da qual se dialoga com o aluno pode ser uma barreira ou não para o seu aprendizado. Sforni (2015) e Libâneo e Freitas (2006) compreendem que a didática se coloca como fundamental na reflexão docente sobre a técnica e a metodologia que utiliza como instrumento do seu trabalho. Não se tratando de eliminar os conteúdos escolares, mas repensando a didática de ensino, na direção de se promover práticas construtivas à aprendizagem e ao desenvolvimento dos alunos.

A necessidade de organizar e reorganizar as práticas de ensino se mantém como um desafio, uma vez que a escola está calcada em modelos tradicionais de educação. É na busca por pensar em processos educativos colaborativos, que o olhar sobre o audiovisual nos parece um caminho propositivo para a educação e, nesse caso específico, a educação especial. As tecnologias digitais da informação e da comunicação (TDIC), entre as quais está o audiovisual, fazem parte do contexto dos sujeitos na contemporaneidade, a partir das práticas culturais e de cidadania. Geralmente, a escola tem o domínio em reproduzir conteúdo do audiovisual, entre eles filmes e apresentação de conteúdos com o uso do projetor. A produção de audiovisual com os alunos é pouco desenvolvida e, quando se trata da educação especial, esse tipo de atividade é ainda menos recorrente.

Ao realizar um trabalho de produção audiovisual, os sujeitos participantes se envolvem com diferentes etapas e processos inerentes a esse tipo de criação de narrativas imagéticas, que solicitam deles o Interfaces da Educ., Paranaíba, v.11, n.31, p. 388 - 412, 2020 
desenvolvimento/aprimoramento de diversas habilidades e atitudes. Uma delas, diz respeito à criticidade diante das informações. Para Bevort e Belloni (2009) as "novas" competências e os novos modos de aprender estão ligados ao domínio da informação e à comunicação interativa da atualidade. Portanto, o uso de artefatos culturais abarca a apropriação intencionalreflexiva e criativa sobre os conteúdos que circulam nas redes e na sociedade. Fantin $(2014$, p. 62) afirma que:

\footnotetext{
É fundamental pensarmos na perspectiva de um trabalho crítico com as múltiplas linguagens entendidas como um repertório de capacidades correlacionadas. Nesse processo, as multiliteracies intercruzam a arte, a ciência, a narrativa e o lúdico como linguagens fundamentais, em que o sujeito expressa e comunica os seus sentimentos, as suas ideias e as suas experiências das mais diversas formas: orais, escritas, plásticas, corporais, musicais, eletrônicas, audiovisuais e digitais.
}

O educar para a cidadania passa por esses caminhos, considerando as TDIC como parte integrante dessa formação, mas mantendo, antes de qualquer coisa, a abordagem crítica e de resolução de problemas, compreendendo como parte do processo de formação, a leitura e a criticidade. Sendo a escola um lugar propício ao desenvolvimento de diferentes habilidades, cabe ao professor organizar o ensino de modo a favorecer, com que o aluno passe por situações educativas que exijam reflexão e resolução de problemas em contextos além da escrita textual.

Dessa forma, o presente texto busca descrever a metodologia de ensino usada pela professora, ao realizar uma produção audiovisual, com alunos da educação especial, favorecendo o aprendizado do conteúdo escolar, ao desenvolvimento das habilidades de comunicação, sociocognitivas e dos usos das TDIC.

\section{Contextualização da pesquisa}

A pesquisa foi realizada numa escola da rede pública de ensino de uma cidade interiorana do estado do Rio de Janeiro, que atende crianças e jovens do ensino fundamental, mais especificamente na Sala de Recurso 
Multifuncional (SRM). As atividades da pesquisa ocorreram durante o Atendimento Educacional Especializado (AEE) desses alunos.

O espaço é amplo, bem iluminado, arejado e climatizado; conta com estantes, armários com vários jogos pedagógicos, notebooks, impressora, televisão, uma mesa grande redonda e cadeiras, onde é realizada a maioria dos trabalhos.

Os alunos da SRM são atendidos no contraturno do horário na sala regular e o atendimento é realizado de forma individual, em dupla ou trio, conforme o perfil de cada um deles.

Os alunos que fizeram parte da pesquisa têm perfis diferentes em relação ao comportamento e questões da aprendizagem. A escolha foi por afinidade em realizar trabalho em grupo. Apenas um deles - chamado aqui de "N" - é atendido individualmente devido ao grau de sua deficiência. Apresentamos o perfil de cada um dos participantes da pesquisa: 
Quadro 1 - Perfil dos sujeitos da pesquisa

\begin{tabular}{|c|c|c|c|c|c|}
\hline Aluno/Idade & $\mathbf{N}, 14$ & $\mathbf{R}, 14$ & A, 12 & M, 12 & C, 12 \\
\hline Ano escolar & \multicolumn{4}{|c|}{$6^{\circ}$ ano } & $5^{\circ}$ ano \\
\hline Diagnóstico & $\begin{array}{c}\text { Deficiência } \\
\text { múltipla }\end{array}$ & \multicolumn{4}{|c|}{ Deficiência intelectual } \\
\hline AEE & Individual & \multicolumn{4}{|c|}{ Em grupo } \\
\hline Sala regular & \multicolumn{5}{|c|}{ Curriculo adaptado } \\
\hline $\begin{array}{l}\text { Caracteristica } \\
\text { s escolares }\end{array}$ & \multicolumn{3}{|c|}{ Lê, escreve e conversa } & \begin{tabular}{|c|} 
Dificuldade \\
s na leitura \\
e escrita
\end{tabular} & Lê e escreve \\
\hline $\begin{array}{l}\text { Habilidade } \\
\text { Social }\end{array}$ & \multicolumn{2}{|c|}{ Comunicativo } & $\begin{array}{c}\text { Dificuldade } \\
\text { de } \\
\text { socialização }\end{array}$ & Introvertido & $\begin{array}{c}\text { Comunicativ } \\
\text { o }\end{array}$ \\
\hline $\begin{array}{l}\text { Locomove-se } \\
\text { com } \\
\text { autonomia } \\
\text { pela cidade }\end{array}$ & \multicolumn{3}{|c|}{ Sim } & Não & Sim \\
\hline $\begin{array}{l}\text { Matriculado } \\
\text { nessa escola } \\
\text { desde }\end{array}$ & \multicolumn{3}{|c|}{2010} & 2018 & 2010 \\
\hline
\end{tabular}

Fonte: Elaboração própria.

Ao todo, foram realizados quatro encontros, durante o mês de junho de 2018, com três grupos de alunos, organizados de acordo com o horário de atendimento que fazem regularmente, com a duração de uma hora por encontro. Os encontros na SRM foram filmados e fotografados ${ }^{3}$. Posteriormente, realizamos as anotações que envolviam questões como: as reações, emoções, negativas e fatos que chamaram nossa atenção no ato da tarefa. Como expresso no quadro a seguir, houve duas atividades (leitura e painel) antes da produção da animação.

\footnotetext{
3 Todas as ações desta pesquisa foram autorizadas pelos responsáveis dos alunos.

Interfaces da Educ., Paranaiba, v.11, n.31, p. 388 - 412, 2020
} 
Quadro 2 - Atividades desenvolvidas

\begin{tabular}{|c|l|}
\hline Encontros & \multicolumn{1}{c|}{ Atividades na SRM } \\
\hline $1^{\circ}$ & $\begin{array}{l}\text { Leitura compartilhada } \\
\text { Painel explicativo do conteúdo }\end{array}$ \\
\hline $2^{\circ}$ & $\begin{array}{l}\text { Painel explicativo do conteúdo - } \\
\text { Professora e alunos } \\
\text { Painel explicativo do conteúdo - alunos } \\
\text { Animação a partir do conteúdo }\end{array}$ \\
\hline $3^{\circ}$ & $\begin{array}{l}\text { Assistir a curtas realizados com } \\
\text { animação } \\
\text { Escolher outra ecologia do conteúdo } \\
\text { Pensar e construir elementos para o } \\
\text { cenário }\end{array}$ \\
\hline $4^{\circ}$ & $\begin{array}{l}\text { Montar o cenário } \\
\text { Produção da animação (foto e edição) }\end{array}$ \\
\hline
\end{tabular}

Fonte: Elaboração própria.

Sem pretensão de avaliar dentro de um padrão de certo ou errado, mas com o propósito de realizarmos algumas inferências e compartilharmos o processo didático realizado, passamos a descrever, de forma sucinta, as atividades de leitura e painel, desenvolvidas pela professora, que dão suporte à atividade da animação audiovisual, foco principal deste artigo.

\section{Processos didáticos}

Uma das atribuições do professor do AEE é "estabelecer articulação com os professores da sala de aula comum, visando à disponibilização dos serviços, dos recursos pedagógicos e de acessibilidade e das estratégias que promovem a participação dos alunos nas atividades escolares." (BRASIL, 2009 , p. 3). Nesse sentido, a professora da SRM apresentou um projeto para a professora de ciências, com objetivo de incentivar, orientar e construir junto uma adaptação curricular, de modo que esta pudesse visualizar e viabilizar futuramente o aprendizado dos alunos, percebendo as 
possiblidades entre o aprendizado da pessoa com deficiência intelectual através de recursos pedagógicos mais adequados.

As professoras se reuniram por duas vezes para o planejamento das ações do projeto. A proposta se desdobrou em atividades na SRM, na sala do ensino regular e, por fim, em uma avaliação final entre pares sobre o processo. O foco deste artigo é analisar a atividade desenvolvida com o uso do celular na sala de recursos, portanto, não evidenciaremos as práticas ocorridas na sala de aula regular.

\subsection{Mediação pedagógica: leitura compartilhada}

O primeiro encontro foi dedicado à leitura compartilhada do conteúdo, como expresso no livro didático "Projeto Telális $-6^{\circ}$ ano - Ciências. Planeta Terra", Unidade 1, Capítulo 3: "Relações entre os seres vivos". A professora usou uma estratégia diferenciada para a leitura, marcou no próprio livro, com marca-texto amarelo, os pontos (palavra e frases) que os alunos deveriam ficar mais atentos durante a leitura. Ela alternava a leitura com eles e realizava observações em relação às imagens contidas no livro.

Os participantes estavam dispostos um ao lado do outro (quando em grupo) e a professora se posicionou na frente deles. O livro ficava com eles e ela o manteve durante todo o tempo no domínio dos alunos. A professora mediava a leitura, corrigia as palavras lidas de forma incorreta, lia algumas vezes, com o livro na posição certa para eles e de cabeça para baixo para ela.

Percebemos que a mediação pedagógica realizada pela professora permitia a participação dos alunos, a integração do grupo e procurava intervir de modo que fosse compreendido pelos alunos o conteúdo daquela atividade. O conceito de mediação é central na concepção de Vigostki (2009), pois se entende que a relação do homem com a realidade não é um canal direto, mas uma relação mediada pelo o outro, pelos signos e pelos artefatos culturais. Nesse sentido, a mediação pedagógica desenvolvida pelo professor também está no "entre lugar" e tem uma dupla funcionalidade, conforme evidenciam Libâneo (2004) e Sforni (2015). Esta ocorre primeiro na relação do aluno e do objeto de conhecimento, quando o professor estabelece qual conteúdo será evidenciado e a segunda mediação é a didática, que garante Interfaces da Educ., Paranaíba, v.11, n.31, p. 388 - 412, 2020 
as condições e os meios para que os alunos se relacionem com o conhecimento. Nesse momento, o professor se coloca como agente promotor de ações na direção do aprendizado do aluno.

\subsection{Construção colaborativa}

A segunda atividade do primeiro encontro foi realizada logo depois da leitura. Para a montagem do painel, a professora preparou um material em papel separado pelas sessões: imagens, palavras e conceitos. As imagens eram coloridas, alguns expressavam os mesmos desenhos do livro. As palavras eram os nomes das ecologias entre seres vivos (conteúdo do livro) e os conceitos eram frases explicativas sobre cada uma das ecologias. Esse material foi disposto na mesa, próximo aos participantes.

Os alunos se mantiveram na mesa, a professora pediu para eles ficarem com o livro aberto, e iniciou colocando uma imagem idêntica ao título do capítulo do livro "Relações entre seres vivos". Em seguida, explicou o que significava esse título e perguntou aos participantes: "O que são seres vivos?" Eles deram alguns exemplos e, na sequência, ela pegou da sessão dos conceitos uma das fichas onde estava escrito: "tudo que nasce, cresce, reproduz e morre" e colocou abaixo do título. Ela solicitou que os alunos pegassem imagens de seres vivos que foram colocadas abaixo da ficha de conceito, como indicou a professora.

A professora perguntou a eles qual era o primeiro ponto que o texto do livro abordava, os alunos buscaram a resposta no texto e um deles disse: "sociedade". Ela pediu para buscar por essa palavra na sessão das palavras, e explicou o que é viver em sociedade. Então, pediu aos participantes que procurassem na sessão dos conceitos qual era, então, o que melhor se encaixava nesse conceito. Ao identificarem a frase correta, eles colocavam-na abaixo da palavra "sociedade" e, dessa vez, não precisou a indicação da professora quanto ao local a ser colocado. A professora pediu para achar na sessão das imagens quais delas representavam uma sociedade, e os alunos selecionaram e posicionaram as que encontraram abaixo do conceito, a imagem de uma colônia de abelhas. 
Sempre seguindo a ordem: "palavra, conceito, imagem" e com a mediação intensa da professora, o painel foi sendo criado. Ela dava o comando, aguardava a busca dos alunos pelas sessões e, quando necessário, orientava a direção de procura e organização na mesa (local onde o painel foi montado). Ela refazia a pergunta quando achava que eles não estavam entendendo. Quando percebia que um aluno estava respondendo mais que o outro, pedia para esperar e dava a chance ao aluno mais quieto. O livro didático ficou próximo aos participantes e era utilizado como apoio, quando necessário, principalmente para saber a sequência. As imagens que eram iguais às do livro foram colocadas no painel sem muito debate. As imagens diferentes, quando não eram tão evidentes para entender, às vezes levantavam uma dúvida, que era sanada pela professora ou algum colega respondia.

Imagem 1 - Painel construido na atividade

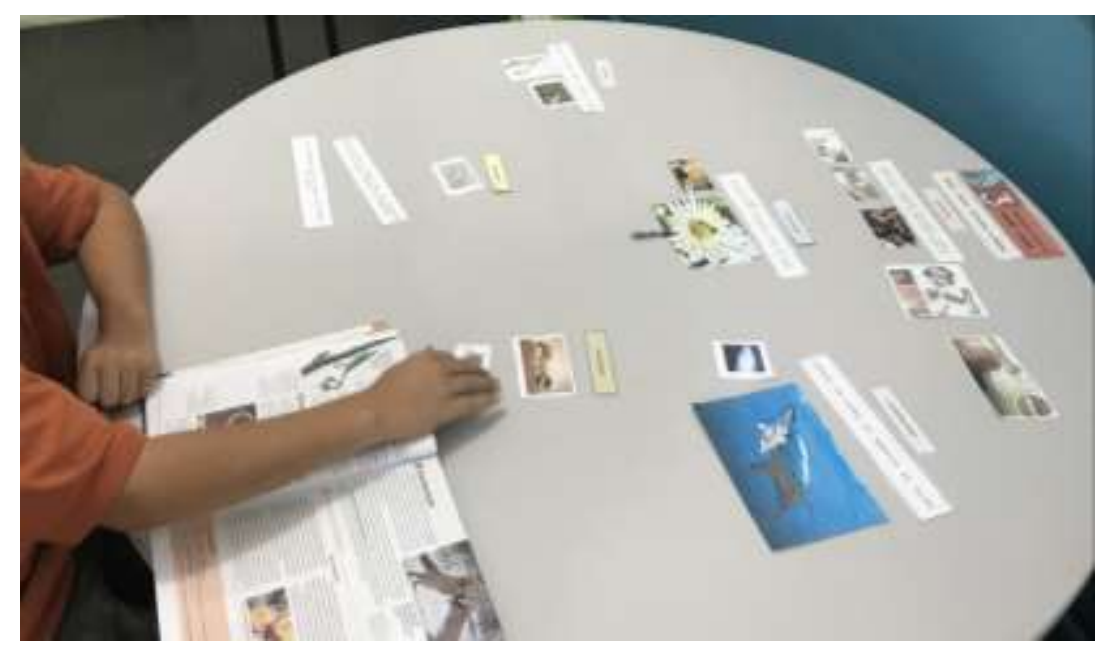

Fonte: Arquivo da pesquisa.

Após o painel montado na mesa, eles realizaram uma revisão de todo o conteúdo, de forma oral e apontando para a sequência do trabalho. A professora completava a fala quando os alunos demostravam dúvidas. Para finalizar o painel, a professora retirou todas as imagens, deixando somente as palavras e os conceitos, e solicitou aos alunos que recolocassem as imagens nos lugares, de acordo com o significado.

Propiciar o acesso aos bens culturais e a aprendizagem são princípios contidos no documento da Política Nacional de Educação Especial na Perspectiva da Educação Inclusiva (BRASIL, 2008), com vistas ao Interfaces da Educ., Paranaíba, v.11, n.31, p. 388 - 412, 2020 
desenvolvimento humano. O que se mostra um desafio é criar modos de acesso ao conhecimento por trás dos conteúdos escolares.

Sforni (2015) apresenta cinco principios norteadores para o trabalho do professor, baseada na perspectiva histórico-cultural. A autora denomina tais princípios como "experimento didático", composto por:

1) Avaliação do desenvolvimento do aluno: o que costumamos chamar de diagnóstico inicial, identificando o nivel atual e planejando ações para atingir o nível esperado. A autora orienta que sejam realizadas atividades que mobilizem as funções cognitivas, usando as habilidades de comunicação para impulsionar o pensamento e a linguagem.

2) Conteúdo aliado à aprendizagem ativa, no sentido de promover e incentivar a participação do aluno. Ao final, sugere-se a realização de uma sintese conceitual do conteúdo, como forma de colocar em movimento as ações mentais. O aluno deve estar envolvido numa situação problema, que desencadeia a produção conceitual.

3) Atividade mental como atividade principal do aluno, ao estar consciente da sua ação em relação ao conteúdo. Libâneo (2004) compreende que a estrutura da atividade é constituída pelas necessidades, motivos, finalidades e condições de realização da atividade, que geram orientações para um objeto. Nesse sentido, cabe como ação docente, planejar atividades voltadas à atenção do aluno e promover diálogo nesse fazer.

4) Linguagem como mediadora de todo o processo, entre o caminho planejado e a prática materializada.

5) Levar o aluno a perceber que conceito é o instrumento de intervenção no mundo, mediador das interações entre o sujeito e a sua atuação nos instrumentos produzidos historicamente, assim, levar a novos problemas e conceitos.

Portanto, a construção colaborativa de uma atividade exige a mediação pedagógica do professor durante todo o processo, a fim de não se perder de Interfaces da Educ., Paranaíba, v.11, n.31, p. 388 - 412, 2020 
vista os objetivos do trabalho. A escola tem como prática positiva o incentivo à participação dos alunos durante uma aula, a perspectiva é quanto à dificuldade que um aluno possa ter, de modo, que não seja encarada como uma negativa ao aprendizado, mas visto como uma possibilidade dentro do seu processo de aprendizagem. A construção colaborativa, por meio das dinâmicas educativas em sala de aula, contribui para potencializar as habilidades cognitivas e sociais nos alunos.

\subsection{Produção audiovisual}

A terceira atividade realizada com esses alunos foi a produção da animação com base no painel (Imagem 1). Para tanto, foi utilizado um celular com o aplicativo gratuito Stop Motion, desenvolvido pela Cateater.LLC. Resumidamente, os alunos deveriam abrir o aplicativo, fotografar as cenas (procurando realizar pequenas mudanças na posição do objeto que se pretende causar a impressão de movimento), editar (opção de cada usuário) e acionar o play no aplicativo para as fotos se movimentarem, tornando-se animadas. Os alunos não conheciam esse aplicativo e demostraram não ter habilidades técnicas suficientes para fotografar. Diante disso, durante o processo, a professora ensinava alguns procedimentos como focar, posicionar as mãos da melhor maneira para o clique da foto, não tremer e escolher o melhor ângulo para cada foto. Ela realizou junto a eles a edição composta de escolha do tema (fundo), créditos (título, nome deles e palavra final), velocidade da animação e a música de fundo. O cenário foi criado sobre a mesa (lisa e cinza), com alguns objetos selecionados das estantes pelos alunos.

O aplicativo Stop Motion foi desenvolvido para o público em geral, e não encontramos referência específica de uso para usuários com deficiência intelectual, mas era conhecido da professora, que vislumbrou a possibilidade de uso na sala de recursos. Principalmente por entender que o celular é um artefato cultural de uso dos alunos e que seria apropriado desenvolver com eles uma atividade que envolvesse o celular, aplicativos e conteúdos escolares. 
Para melhor entendimento sobre o processo, escolhemos a animação produzida por "A", pela quantidade de frames (quadros) que, no total, se constituiu de: 1 frame com a imagem de fundo dos créditos de início e término da animação (Imagem 2); 1 frame "primeiro plano" que serve de moldura (Imagem 3) e outros 38 frames da narrativa (Quadro 3).

Imagem 2 - Montagem com frames dos créditos de abertura e encerramento da animação
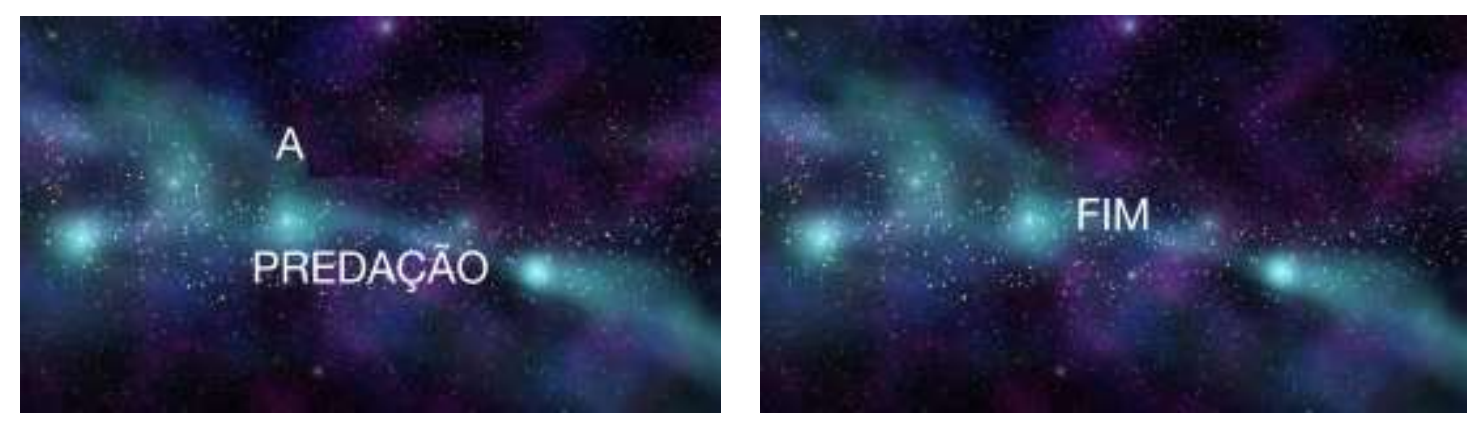

Fonte: Material da pesquisa.

Imagem 3 - Montagem com as cenas criadas por " $\mathrm{A}$ "

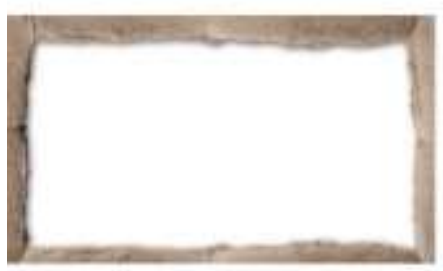

Frame: Primeito plano

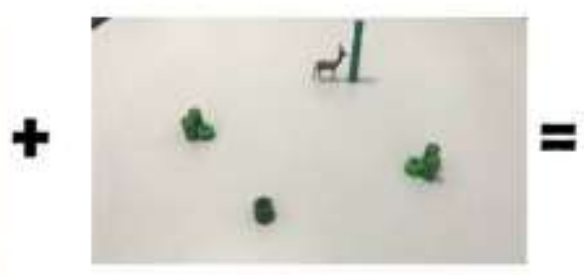

Frame: Cena

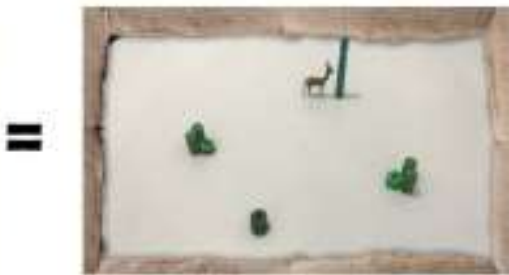

Frame: Cena edtitada

Fonte: Material da pesquisa.

Passamos a recontar a história desenvolvida por "A", a partir de seu entendimento sobre a ecologia "Predação" e sobre as técnicas da animação pelo aplicativo. Sabendo que o aluno escolheu os animais e os elementos de cor verde fazem referência à floresta. No Quadro 3, apresentamos a quantidade de frames que o aluno usou para criar cada uma das cenas. Utilizamos apenas um dos frames para ilustrar a cena construída. 
Quadro 3 - Montagem com a produção final

\begin{tabular}{|l|c|c|}
\hline \multicolumn{1}{|c|}{ Cena } & Imagem representativa & $\begin{array}{c}\text { Total de } \\
\text { frames }\end{array}$ \\
\hline Cervo na floresta & & 4 \\
\hline Chegada do tigre & & 11 \\
\hline Aproximação do & & 1 \\
\hline tigre em direção & & 1 \\
\hline ao cervo & & 1 \\
\hline Perseguição do \\
tigre ao cervo
\end{tabular}

Fonte: Material da pesquisa.

O frame vai sendo montado de um a um e pode ser acionado o play a qualquer momento para ver como está a animação.

Após a etapa das fotografias, iniciando a edição, a primeira ação foi rever os frames, procurando por fotos desfocadas. O aluno selecionou as 
fotos a serem excluídas da sequência, com o celular na mão. Talvez, o melhor fosse utilizar de um tripé, garantindo mais acerto quanto ao foco.

O aplicativo tem área específica para os créditos, plano de fundo, aceleração, entre outros elementos. $\mathrm{Na}$ medida em que as escolhas são feitas, a mudança aparece no mesmo instante na produção, o que percebemos ser uma tarefa positiva para o aluno em questão, pois, enquanto na fotografia a professora ficou orientando que os alunos tivessem um pouco o conhecimento da técnica, na edição, apesar de mediar os passos no aplicativo, ela deixou a livre escolha da composição dos créditos, plano de fundo e aceleração.

Trazemos (Imagem 4) as telas de edição que foram utilizadas no aplicativo para ilustrar as opções disponiveis para a montagem da animação.

Imagem 4 - Montagem com prints das opções do Stop Motion
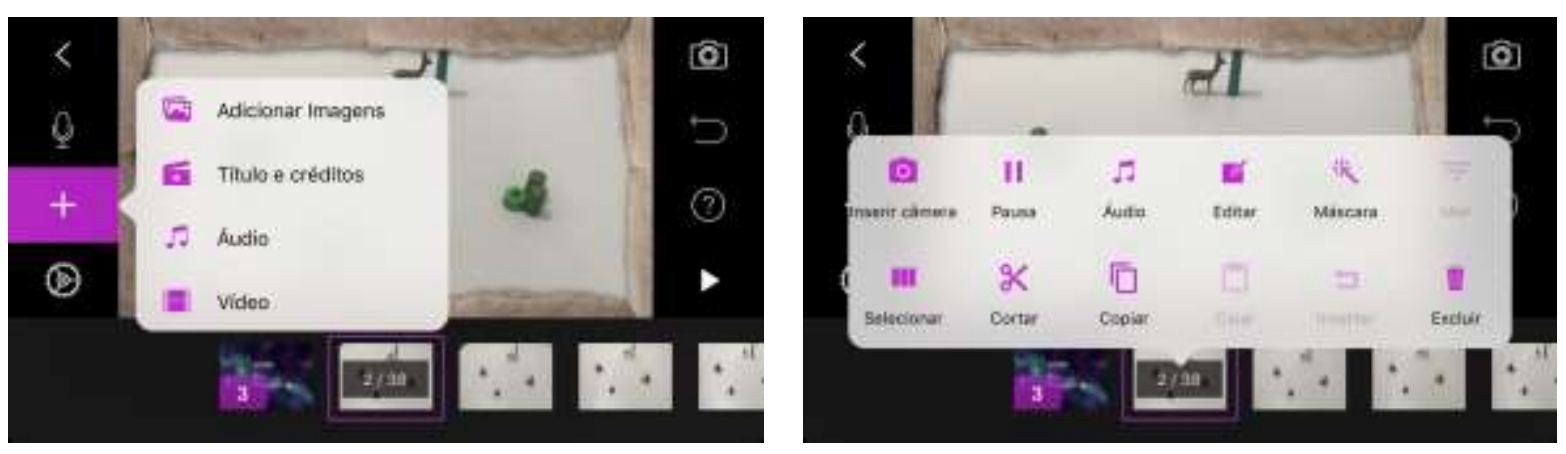

Fonte: Material da pesquisa.

A edição exigiu do aluno processos mentais complexos, abrir a área para edição, ler e identificar o local exato que se quer editar e nele realizar a edição - processo de escrita e escolha compativel com a narrativa. Entre as decisões tomadas por ele durante a edição, destacamos a escolha do destaque em vermelho, no último frame, caracterizando o sangue do animal, além do plano detalhe usado para dar maior foco à predação. Trata-se de um diferencial em relação às demais cenas, feitas em plano aberto.

As técnicas usadas no audiovisual abrem para outra discussão que não é nosso propósito neste momento, porém, percebemos que o aluno "A" teve uma maior desenvoltura que os demais, na realização das fotos (escolha 
dos planos) e da edição do vídeo (escolha dos frames). Em conversa informal, ele mencionou que tem o seu próprio celular e usa para tirar fotos e para conversar com amigos, o que demonstra que ele possui alguma experiência prévia com manipulação da câmera do celular e das próprias fotografias.

\section{Narrativa audiovisual para o desenvolvimento de habilidades de comunicação e sociocognitivas}

O conceito de predação ou predatismo envolve a relação ecológica da alimentação, quando um predador se alimenta de uma presa de espécie diferente da sua. Isso foi evidenciado nas cenas produzidas e animadas da produção de "A". Logo após ter elaborado um quadro com imagens prédeterminadas relacionadas ao conteúdo, ele transpôs o seu entendimento sobre o conceito em forma de cenas, configurando-se em uma narrativa com suporte digital. Vemos muito menos esse gênero narrativo que, por exemplo, as histórias de escrita sobre a gravura. Porém, tanto numa narrativa escrita, quanto numa audiovisual, para que a comunicação seja estabelecida é necessária a execução de um sequenciamento coerente. Em todas as narrativas, o emissor deve ter atenção às estruturas de introdução, orientação espacial e temporal, compilação e resultado (começo, meio e fim), para que o receptor possa compreender a mensagem veiculada (SPERB, 2010).

O aprendizado das narrativas na escola começa de forma gradativa, primeiramente pela oralidade do aluno (professora-aluno/ aluno-aluno e no coletivo), ao iniciar o processo da escrita são incorporadas frases nas atividades que envolvem as narrativas, a seguir se avança a pequenos textos. A partir da apropriação maior da língua escrita, os textos escritos pelas crianças, no processo de alfabetização se tornam maiores e mais complexos.

Desenvolver atividades de estudo que envolvam a transposição de narrativas para o contexto das mídias, nos parece um caminho favorável ao desenvolvimento de habilidades de comunicação, voltadas ou não para alunos com deficiência. Girardello (2012) realizou um trabalho de pesquisa na rede municipal de ensino de Nova York, e apresentou algumas considerações sobre um projeto de construção colaborativa de parâmetros Interfaces da Educ., Paranaíba, v.11, n.31, p. 388 - 412, 2020 
curriculares, que envolve arte, trabalho pedagógico de linguagem e audiovisual. No eixo de produção da narrativa audiovisual/midiática, destacamos o relato que uma professora do $2^{\circ}$ ano do ensino fundamental concedeu à pesquisa, tendo utilizado o Voice Thread ${ }^{4}$ para estimular a criação de histórias nas crianças. A turma tinha como característica os alunos serem de diferentes nacionalidades, que foram encorajadas a aprender de forma colaborativa para resolver os problemas encontrados na utilização do Voice Thread. O trabalho desenvolvido pela professora expressa um esforço de incorporar o letramento digital ao contexto das aprendizagens. Os alunos precisam seguir um processo para a atividade ser produzida. "Cada aluno desenvolve um roteiro narrativo e grava sua voz em um áudio, narrando a sequência de imagens selecionadas (na web) e figuras criadas por eles próprios, cuidadosamente colocadas em ordem." (GIRARDELLO, 2012, p. 85).

O que se apresenta na pesquisa com alunos com deficiência intelectual e na turma de Nova York expressa como unidade comum o planejamento didático e a colaboração entre os participantes na busca pelas informações que precisavam. Não era de dominio coletivo as técnicas dos aplicativos, a descoberta sobre as funcionalidades tornou-se um aprendizado colaborativo. Embora a pesquisa de Girardello (2012) tenha sido realizada com alunos sem deficiência, podemos comparar seus resultados aos ganhos dos alunos de nossa pesquisa, tendo por base o aprendizado colaborativo a partir da busca e uso de funcionalidades do Stop Motion.

Os alunos não conheciam o aplicativo Stop Motion, mas isso não foi impeditivo para realização da atividade, pois usar o celular e fotografar faz parte da cultura deles. Além disso, os alunos têm o aprendizado das estruturas narrativas, o que garantiu o entendimento sobre a produção, mesmo sem a utilização de palavras. Recorremos a pesquisas com alunos sem deficiência, pois ainda é escassa a produção desse tipo de atividade com

\footnotetext{
${ }^{4}$ Voice Thread é um serviço que associa imagens, documentos e vídeos com comentários em voz (através de microfone ou telefone), texto, arquivo de áudio ou vídeo com webcam, criando apresentações multimídias que podem ser discutidas e comentadas pelos usuários. Disponivel em: https://voicethread.com/.
} 
alunos deficientes. Esta é outra questão que este artigo considera relevante para maior aprofundamento nesse campo de pesquisa.

É possivel compreendermos toda a narrativa pelos sequenciamentos escolhidos e movimentos utilizados, o que indica um processo simbólico sobre os conceitos básicos da narrativa. Para Leontiev et al (2005), o processo educativo é de formação social e individual, do qual a comunicação exerce fator ao desenvolvimento. Na expressão de suas ideias o sujeito é tencionado a organizar seus pensamentos em função de se fazer entender pelo outro, um processo ativo da cognição em busca da interação entre a palavra construída na mente, a falada, o que ouve ao redor (dito pelo outro) e a compreensão sobre isso. O movimento é interativo, de construção e reconstrução dialógica no tempo ali presente, o que a nosso ver gera ganhos cognitivos a formação desse sujeito.

Algumas pesquisas sobre produção audiovisual na escola (FANTIN, 2014; FONSECA, 2019; LABRUNIE, 2017; TOLEDO, 2014) confirmam que as atividades inerentes a esse tipo de produção podem contribuir para o desenvolvimento de habilidades sociocognitivas, como capacidade de tomada de decisões, atuação em tarefas em equipe, argumentação e defesa de ideias em grupo, entre outras.

Segundo Ferrés (2007), as competências audiovisuais, como parte das competências midiáticas, devem ser levadas em consideração nos processos de ensino e aprendizagem, embora esta não seja uma realidade e ainda existam poucas tentativas para se definir uma pessoa competente em comunicação audiovisual. Tal fato pode estar relacionado à falta de sistematização do que vem sendo produzido pelas pesquisas sobre o tema, devido aos diversos âmbitos em que essas competências se inserem (comunicação, educação, psicologia, sociologia), com propostas, indicadores e terminologias distintas (AMOR PÉREZ; DELGADO, 2012). Pereira et al (2018) analisam a produção midiática individual e coletiva de jovens em diferentes contextos e destacam que é preciso considerar a diferença entre as habilidades desenvolvidas em atividades coletivas:

A principal diferença está nas habilidades que eles desenvolvem ao longo do processo. Quando realizam produções em grupo, adquirem outras habilidades associadas à gestão social, como a capacidade de Interfaces da Educ., Paranaíba, v.11, n.31, p. 388 - 412, 2020 
coordenar ou liderar, por exemplo. Deve-se notar que, na maioria dos casos, as produções coletivas são feitas dentro do grupo de pares. ${ }^{5}$ (PEREIRA et al, 2018, p. 106).

É possivel considerar, então, que atividades com produção audiovisual podem propiciar o desenvolvimento de habilidades e aprendizagens a partir das interações dos envolvidos entre si e com as tecnologias utilizadas, sendo, portanto, um momento de interação social em que ocorre o desenvolvimento sociocognitivo dos alunos, e de habilidades relacionadas ao manuseio das tecnologias. No caso tratado neste artigo, as habilidades sociocognitivas foram desenvolvidas mais na etapa de produção do quadro de conceitos, quando todos os alunos precisaram ouvir uns aos outros e trabalhar em equipe para a organização das imagens de acordo com os conceitos trabalhados pela professora.

Em relação às habilidades técnicas inerentes à produção audiovisual em si, podemos indicar que durante as escolhas de imagens para a animação, o aluno "A" precisou organizar o material a ser utilizado, escolher os personagens, separar e dispor os objetos que havia disponivel para cada uma das cenas, descartar imagens irrelevantes, montar as imagens criando uma narrativa crivel, entre outras ações. Ao analisar os frames capturados e selecionados por esse aluno (Quadro 1), vale destacar, na cena em que o tigre se aproxima do cervo, a escolha proposital de retirar elementos representativos da floresta (cor verde), que não estão mais no "assunto" principal da cena. Esse fato indica que o aluno resolveu usar um segundo cenário, diferenciando e evidenciando a caça em si, colocando o foco naquilo que pretendia mostrar. Trata-se, portanto, de uma clara demonstração de que ele entende o que a informação de chegar mais perto de um assunto específico representa no audiovisual, utilizando esse recurso em seu filme.

A promoção de atividades como essa se torna interessante, ao pensarmos na interação dos alunos com o mundo a partir do audiovisual. Norton $(2013$, p. 47) considera que a influência do cinema na relação do

5 Tradução livre do original: "The main difference is in the skills they develop through the process. When they carry out group productions, they acquire other skills associated with social management, such as the ability to coordinate or lead, for example. It should be noted that in most cases collective productions are made within the peer group."

Interfaces da Educ., Paranaíba, v.11, n.31, p. 388 - 412, 2020 
homem com o mundo pode ser transformadora, entre outros motivos, pois: “a relação que o homem estabelece com o mundo se transforma pelos recursos da técnica cinematográfica. Por meio da montagem, das lentes e da pausa, o cinema desautomatiza nosso olhar para a realidade." O olhar mais atento para as imagens produzidas, diferente daquele voltado a fotos do cotidiano, e, consequentemente, a criação de outras possibilidades para determinadas cenas, pode ser considerado como uma desautomatização do olhar, no caso descrito neste artigo.

Essa atividade demandou do aluno "A" uma postura criativa voltada para um produto audiovisual. Para Fresquet (2012, p. 26): “A relação com o mundo atravessada pela câmera produz uma determinada vivência para o aprendente/espectador criador, que é fortemente transformadora." Essa "transformação" que o audiovisual pode proporcionar às situações de aprendizagem está voltada ao interesse, engajamento, produção, autoria, criatividade, imaginação e participação dos sujeitos em processos que trazem ao primeiro plano suas próprias criações. Se pensarmos em alunos de educação especial esse protagonismo se agiganta, uma vez que há poucas metodologias definidas para atividades de produção audiovisual destinadas a eles. Infelizmente não foi possível realizar atividades mais livres com esses alunos, em que a criatividade estivesse a serviço da imaginação e de maior liberdade para criação, sem que a produção esteja voltada a conteúdos escolares. Porém, podemos considerar esta como uma primeira aproximação desses alunos com produção audiovisual, sendo mais confortável a condução dentro de um projeto da escola e, mais especificamente, da professora de ciências.

\section{Considerações finais}

Sabemos das dificuldades quanto à infraestrutura que afeta muitas das escolas públicas brasileiras, e mesmo diante das diversidades é possivel evidenciar práticas propositivas e criativas na educação e, mais especificamente, na educação especial. A unidade escolar pesquisada se enquadra nesse perfil, localiza-se em um morro próximo ao centro da cidade, atende a um público da pré-escola ao $7^{\circ}$ ano de escolaridade e tem sido Interfaces da Educ., Paranaíba, v.11, n.31, p. 388 - 412, 2020 
apontada como uma escola inclusiva pelas práticas com os alunos com necessidades educacionais especiais (deficiência intelectual, deficiência múltipla, deficiência visual).

Tendo um público diverso, as práticas de ensino também acompanham os diferentes modos de aprender. Dessa forma, a metodologia utilizada pelo professor vai fazer a diferença em sala de aula. Neste artigo, buscamos apresentar de forma detalhada o processo de ensino, com o uso do audiovisual, e procuramos refletir sobre os impactos desse fazer junto aos alunos. As habilidades de comunicação e sociocognitivas de trabalhar em grupo aparecem em destaque na prática educativa com uso do audiovisual.

Para Leontiev et al (2005), a comunicação é a atividade principal do ser humano, aquela que o distingue dos demais seres. Ela estrutura a linguagem e organiza as construções do indivíduo na sociedade. Com isso, trabalhar de modo a desenvolver as habilidades de comunicação, em sujeitos com deficiência intelectual, é fator primordial para seu desenvolvimento. A "assunção da tecnicidade midiática como dimensão estratégica da cultura", como entende Martín-Barbero (2014, p. 44), demanda da escola e dos professores, por extensão, a inserção de "novas figuras e campos de experiência em que se processam os intercâmbios entre escrituras tipográficas, audiovisuais e digitais, entre identidades e fluxos, assim como entre movimentos cidadãos e comunidades virtuais.” Assim, acreditamos que atividades com produção audiovisual podem contribuir para o desenvolvimento de competências e/ou habilidades necessárias às aprendizagens promovidas na escola e também na educação especial, caso tenham objetivos e procedimentos bem definidos.

Os estigmas incorporados aos alunos da educação especial, como sendo pessoas incapazes de formular uma opinião, muitas vezes impedem que o desenvolvimento das habilidades apresentadas nesse texto seja realizado. É comum presenciarmos atitudes dos adultos tolhendo a opinião da pessoa com deficiência, sem perguntar diretamente a ela qual sua impressão e escolha sobre determinada atividade. Nessa experiência com produção audiovisual, todas as escolhas para a criação da história, assim como as decisões sobre a captura e seleção das imagens para compor a Interfaces da Educ., Paranaíba, v.11, n.31, p. 388 - 412, 2020 
Tecnologias digitais como metodologia...

animação final, foram tomadas pelos alunos, ouvindo seu processo de tomada de decisão para o produto final. Muitas pesquisas buscam "dar voz" aos sujeitos. Acreditamos que está na hora dar ouvidos a essas vozes e se a produção audiovisual pode ser um caminho para isso, sigamos por ele.

\section{Referências}

AMOR PÉREZ, M.; DELGADO, A. De la competencia digital y audiovisual a la competencia mediática: dimensiones e indicadores. Comunicar: Revista Científica de Educomunicación, v. 20, n. 39, p. 25-34, 2012.

BÉVORT, E.; BELLONI, M. L. Mídia-educação: conceitos, história e perspectivas. Revista Educação e Sociedade. Campinas, vol. 30, n. 109, p. 1081-1102, set./dez. 2009.

BRASIL. Ministério da Educação. Política Nacional de Educação Especial na Perspectiva da Educação Inclusiva. Brasília, DF: MEC/SECADI, 2008.

BRASIL. Ministério da Educação. Resolução n 4, de 2 de outubro de 2009.

Define Diretrizes Curriculares Nacionais Gerais para a educação básica modalidade da educação especial. Diário Oficial [da] República Federativa do Brasil, Brasília-DF, 5 out. 2009, Seção 1, p. 17.

FANTIN, M. Audiovisual na escola: abordagens e possibilidades. In: BARBOSA, M. C. S.; SANTOS, M. A. dos. (Org.). Escritos de alfabetização audiovisual. Porto Alegre: Libretos, 2014. p. 47-67.

FERRÉS, J. La competencia en comunicación audiovisual: dimensiones e indicadores. Comunicar: Revista Científica de Comunicación y Educación, v. 15, n. 29, p. 100-107, 2007.

FONSECA, M. J. S. Produção audiovisual em uma escola municipal do Rio de Janeiro: pedagogia audiovisual e habilidades sociocognitivas. 2019. Tese Interfaces da Educ., Paranaíba, v.11, n.31, p. 388 - 412, 2020 
(Doutorado em Educação) - Pontificia Universidade Católica do Rio de Janeiro, Rio de Janeiro, 2019.

FRESQUET, A. M. Cinema e educação: reflexões e experiências com professores e alunos de educação básica, dentro e "fora" da escola. Belo Horizonte: Autêntica, 2013.

GIRARDELLO, G. Narrativa infantil, mídia-educação e novos letramentos: um percurso de pesquisa. Revista Educação On-line PUC-Rio, Rio de Janeiro, n. 11, p. 73-88, 2012.

KASSAR, M. C. M. Funções mentais superiores e a formação da consciência em sujeitos com deficiência mental grave: implicações pedagógicas. In: SMOLKA, A. L. B.; NOGUEIRA, A. L. H. (Org.). Estudos na perspectiva de Vygotsky: gênese e emergência das funções psicológicas. Campinas: Mercado das Letras, 2013. p. 151-172.

LABRUNIE, M. das G. L. A produção de vídeos na escola: um estudo exploratório. 2017. Tese (Doutorado em Educação) - Universidade Estácio de Sá, Rio de Janeiro, 2017.

LEONTIEV, A. et al. Psicologia e pedagogia: bases psicológicas da aprendizagem e do desenvolvimento. São Paulo: Centauro, 2005.

LIBÂNEO, J. C. A aprendizagem escolar e a formação de professores na perspectiva da psicologia histórico-cultural e da teoria da atividade. Educar em Revista, Curitiba, n. 24, p. 113-141, 2004.

LIBÂNEO, J. C.; FREITAS, R. A. M. de M. Vygotsky, Leontiev, Davydov: três aportes teóricos para a teoria histórico-cultural e suas contribuições para a didática. In: CONGRESSO BRASILEIRO DE HISTÓRIA DA EDUCAÇÃO. 4., 2006. Anais [...]. Goiânia, 2006. 
Tecnologias digitais como metodologia...

MARTÍN-BARBERO, J. A comunicação na educação. São Paulo: Contexto, 2014.

MENDES, E. G. A radicalização do debate sobre inclusão escolar no Brasil. Revista Brasileira de Educação, v. 11, n. 33, p. 387-405, 2006.

NORTON, M. Cinema oficina: técnica e criatividade no ensino de audiovisual. Niterói: Editora UFF, 2013.

PAIXÃO, K. de M.; OLIVEIRA, A. A. S. de. Deficiência intelectual e linguagem escrita: discutindo a mediação pedagógica. Horizontes, v. 36, n. 3, p. 86-98, 2018.

PEREIRA, S. et al. Media uses and production practices: case study with teens from Portugal, Spain and Italy. Comunicación y Sociedad, n. 33, p. 89114 , sep./dec. 2018.

PINO, A. A interação social: perspectiva sócio-histórica. Ideias, São Paulo, n. 20, p. 49-58, 1993.

PLETSCH, M. D. A escolarização de pessoas com deficiência intelectual no Brasil: da institucionalização às politicas de inclusão (1973-2013). Arquivos Analiticos de Políticas Educativas, v. 22, n. 81, 2014.

SFORNI, M. S. de F. Interação entre didática e teoria histórico-cultural. Educação e Realidade, Porto Alegre, n. 2, p. 375, 2015.

SPERB, T. M. Gêneros narrativos e desenvolvimento. In: EISENBERG, Z.; PARENTES, M. A. de M. P. (Org.). Psicologia da linguagem: da construção da fala às primeiras narrativas. São Paulo: Vetor, 2010. p. 155-184. TOLEDO, M. Audiovisual: uma revolução em potencial para a sua sala de aula. In: BARBOSA, M. C. S.; SANTOS, M. A. dos. (Org.). Escritos de alfabetização audiovisual. Porto Alegre: Libretos, 2014.p. 137-153. Interfaces da Educ., Paranaíba, v.11, n.31, p. 388 - 412, 2020 
Kelly Maia Cordeiro e Mirna Juliana Santos Fonseca

VIGOTSKI, L. S. A construção do pensamento e da linguagem. Tradução Paulo Bezerra. 2. ed. São Paulo: WMF Martins Fontes, 2009. 